\title{
Experimental Investigation of the Overlap Process in Metal Droplet Successive Deposition and Solidification
}

\author{
Li Suli, Wei Zhengying, Du Jun, Zhao Guangxi, Wang Xin, Lu Bingheng \\ The State Key Laboratory for Manufacturing Systems Engineering, Xi'an Jiaotong University, Xi'an 710049, China
}

\begin{abstract}
This paper presents a systematic numerical and experimental investigation of the transient transport phenomenon during the overlap of successive aluminum droplets impinging onto a substrate surface. The 3D models based on a volume of fluid (VOF) method were developed to investigate the successive deposition of molten metal droplets on a horizontally fixed aluminum substrate surface. The numerical models are validated with experiments. The comparisons between numerical simulations and experimental findings show a good agreement. The effects of various parameters such as impact velocities, substrate temperatures and droplet diameters on the maximum spread factor during impacting and spreading with solidification of a molten droplet onto an aluminum substrate surface under different parameters were studied. Based on the above research, the relationships between external morphology and internal microstructure were proposed, which was further certified by investigating the overlap of successive droplets.
\end{abstract}

Key words: metal aluminum droplets; successive deposition; morphology; internal microstructure

3D printing by deposition of metal droplets is an additive process in which parts are produced from molten materials in a single operation without the use of any mold or other tooling. Near-net shaped parts are fabricated by sequentially depositing molten droplets layer by layer, which was described by $\mathrm{Li}$ et $\mathrm{al}^{[1]}$. Compared to other metal additive manufacturing technologies, it possesses the obvious advantage of the lower cost of equipment.

Up to now, the two main modes of molten metal droplets deposition technology are continuous jetting (CIJ) and drop-on-demand jetting (DOD). In the DOD mode, the metal is firstly melted in a crucible, and then the liquid metal droplets are ejected from a nozzle under the combined actions of pulse pressure, surface tension and gravity. Finally, the molten droplets are deposited on a moving substrate to form 3D metal components, described by Chao et $\mathrm{al}^{[2]}$. The molten metal in crucible deposits onto a moving substrate with drop-on-demand (DOD). Cao and Miyamoto $^{[3]}$ believed that this technique should be an effective and low-cost method for building metal parts directly.

Metal droplet deposition process was proposed by MIT in early $1990 \mathrm{~s}^{[4]}$. Thereafter, the process was studied in Northeastern University ${ }^{[5]}$, Oak Ridge National Laboratory ${ }^{[6]}$, University of Toronto ${ }^{[7]}$ and so on. However, the research was forced on low-melting point alloys in American Microfab Company ${ }^{[8]}$.

When this technique was applied to aluminum alloy which had more practical value in industrial areas, there were more difficulties because of its higher melting point and larger surface tension than low-melting-point alloys. Currently, the simulation works ${ }^{[9]}$ related to droplets deposition and overlap processes were mainly based on $2 \mathrm{D}$ models, which focused on the single droplet impinging onto a fixed substrate surface. However, 2D models could not provide comprehensive details of the deposition process. Thus, a 3D model has been developed to study complex flows in the successive deposition process of droplets.

Received date: December 25,2016

Foundation item: National Natural Science Foundation of China (31370944); Natural Science Foundation of Shaanxi Province (2014JQ7238); China Postdoctoral Science Foundation (2014M560764)

Corresponding author: Wei Zhengying, Ph. D., Professor, The State Key Laboratory for Manufacturing Systems Engineering, Xi'an Jiaotong University, Xi'an 710049, P. R. China, Tel: 0086-29-82665064, E-mail: zywei@ mail.xjtu.edu.cn 
Ghafouri-Azar et al ${ }^{[10]}$ investigated the impinging of two tin droplets with the diameter of millimeter scale, and simulated the overlap behaviors of droplets. Cheng et $\mathrm{al}^{[8]}$ investigated the overlap process of droplets by assuming that the impinging droplets were pre-deformed into cylindrical discs with a given thickness. The droplet morphology was considered as a disc after impacting onto a substrate and the fluid dynamics of spreading and overlaps of droplets were neglected.

Li et a ${ }^{[11,12]}$ investigated the process of 3D parts by DOD technique; droplets were deposited onto a horizontally moving aluminum substrate surface and overlap each other to form a column. However, successive deposition and solidification of molten metal droplets on the horizontally fixed substrate have not been studied. In the present paper, the successive deposition and solidification of molten aluminum droplets on a horizontally aluminum substrate were numerically simulated by the $3 \mathrm{D}$ model based on the volume of fluid (VOF) method, and the 3D images of morphology evolution of droplets were also discussed.

\section{Modeling and Analysis}

Fig.1 shows the schematic diagram of experimental system, and the experimental system mainly consists of pneumatic droplet generator, droplet deposition system, process monitor system and inert environment control system. The pneumatic droplet generator is used to produce metal droplets on demand. It consists of a droplet controller, a solenoid valve, a crucible, a heating furnace, an electromagnetic device and a nitrogen gas resource. The droplet deposition system is used to form parts by controlling the motion of $3 \mathrm{D}$ platform according to data information. It consists of PMAC (program multiple axes controller), 3D movement platform and deposition substrate. The process monitor system which consists of a CCD camera and an image acquisition card is used to observe the spraying and deposition process of droplets. The inert environment control system is made up of glovebox and gas circulating device. It is used to protect molten metal from oxidizing. The above four parts are coordinately controlled to complete the fabrication of sample by industrial computer.

\section{Experimental Model}

This paper aims at developing a 3D model of successive deposition of uniform molten metal droplets on a stationary substrate. So, the model consisted of the droplets and a substrate, the schematic of the initial free surface and the boundary conditions for the overlap process is shown in Fig.2. A rigid free-slip condition was applied to the substrate surface, and pressure outlet conditions were prescribed for the upper and outer boundaries. In addition to these conditions, an adiabatic boundary condition is applied on all free surfaces.

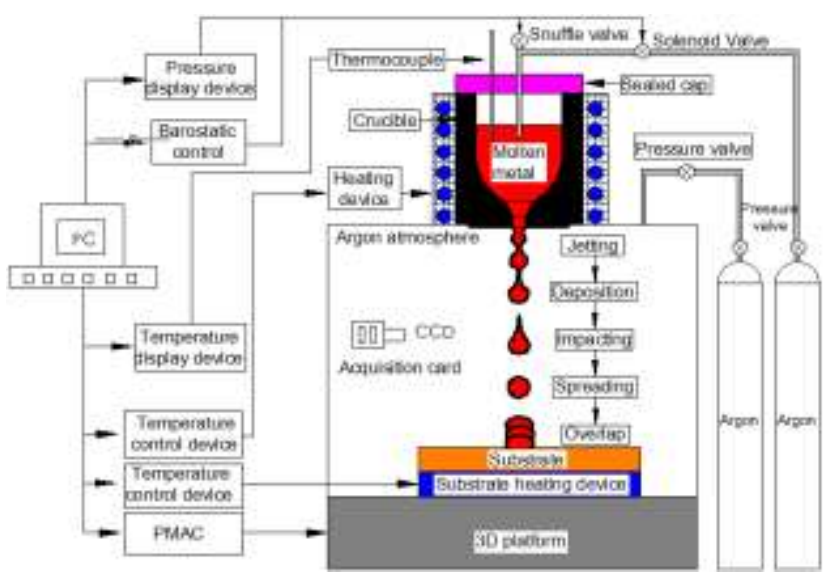

Fig.1 Schematic diagram of experimental system

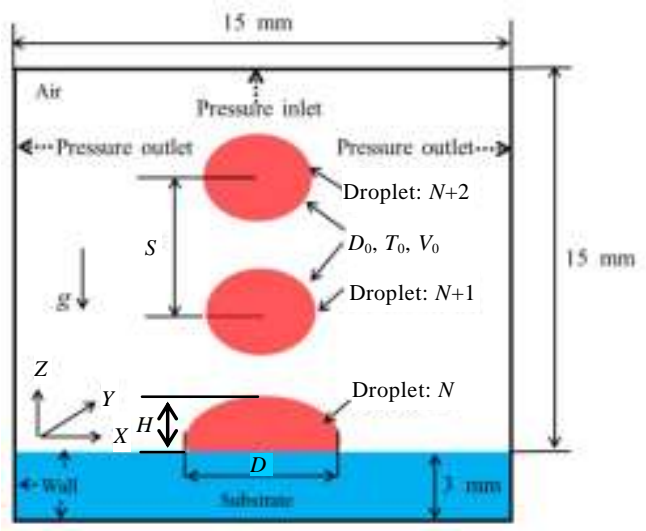

Fig.2 Schematic of the successive droplets deposition

Several assumptions have been made as follows:

(1) The droplets with spherical morphology are generated.

(2) The initial temperature distribution within droplets is uniform.

(3) The surrounding gas is considered as a void region, and thus the heat loss of droplets by convection and radiation are ignored ${ }^{[13,14]}$.

To validate the numerical model, experimental observation of the end-shapes of successive droplets was performed to compare and validate the numerical results. Aluminum droplets with a diameter of $1 \mathrm{~mm}$ and an initial temperature of $935 \mathrm{~K}$ were generated and successively deposited onto an aluminum substrate; the relevant thermo-physical parameters of the molten droplet and the substrate material are listed in Table 1. During deposition, the metal material was firstly melted in a crucible, and then the liquid metal droplets were ejected from a nozzle under the combined actions of pulse pressure, surface tension, and gravity. A nozzle with $0.5 \mathrm{~mm}$ diameter was located at the bottom of the crucible, which was built in a resistance furnace. 
Table 1 Process parameters of deposition experiments

\begin{tabular}{cc}
\hline Parameters & Value \\
\hline Droplet material & Aluminum \\
Droplet surface tension, $\sigma / \mathrm{N} \cdot \mathrm{m}^{-1}$ & 0.8 \\
Droplet velocity, $V_{0} / \mathrm{m} \cdot \mathrm{s}^{-1}$ & 1 \\
Droplet temperature, $T_{0} / \mathrm{K}$ & 935 \\
Substrate temperature, $T_{\mathrm{S}} / \mathrm{K}$ & 300 \\
Droplet diameter, $D_{0} / \mathrm{mm}$ & 1 \\
Inlet pressure, $P_{\mathrm{s}} / \mathrm{MPa}$ & 0.2 \\
Deposition distance, $S / \mathrm{mm}$ & 10 \\
Substrate material & Aluminum \\
Substrate heat capacity, $C_{\mathrm{P}} / \mathrm{J} \cdot \mathrm{kg}^{-1} \cdot \mathrm{K}^{-1}$ & 900 \\
Substrate diffusivity, $\alpha / \mathrm{m}^{2} \cdot \mathrm{s}^{-1}$ & $9.75 \times 10^{-5}$ \\
Substrate thermal conductivity, $\mathrm{k} / \mathrm{W} \cdot \mathrm{m}^{-1} \cdot \mathrm{K}^{-1}$ & 237 \\
\hline
\end{tabular}

Fig.3 shows the evolution of morphology and temperature of a droplet of $1 \mathrm{~mm}$ in diameter with a velocity of $V_{0}=1 \mathrm{~m} / \mathrm{s}$ impacting a substrate surface at different time (Fig. $3 \mathrm{a}_{1} \sim 3 \mathrm{c}_{1}$ ). It is observed that the droplet has been stuck to the substrate and dragged forward. The spreading diameter $D$ shows a trend of increasing, and the spreading height $h$ shows a trend of decreasing, and they are all unchanged after $0.06 \mathrm{~s}$, indicating that the droplet has been completely frozen.

The results show a good agreement with experimental photographs correspondingly (Fig. $3 \mathrm{a}_{2} \sim 3 \mathrm{c}_{2}$ ). The deposition experiment was performed in a glove box under an inert atmosphere with low oxygen content (no more than 150 $\mu \mathrm{L} / \mathrm{L})$. Thus the uniform molten droplets were ejected out from the nozzle. The distance from the nozzle to the substrate was $10 \mathrm{~mm}$, where the morphology and dynamic behavior of the molten droplets tend to be stable. Once the droplet contacted the cold substrate, it was simultaneously cooled by means of heat transfer to the substrate and began to solidify. That was, the base of the droplet initially solidifies and was stuck to the substrate.

\section{Results and Discussion}

\subsection{Deposition of the two successive droplets}

Fig.4 shows the morphology and temperature evolution of overlap between the first droplet and the second droplet during impact on a substrate surface at $300 \mathrm{~K}$ for impact velocities from $0.15 \mathrm{~m} / \mathrm{s}$ to $0.25 \mathrm{~m} / \mathrm{s}$. Due to the substrate without heating, the solidification from bottom to top of the droplets, results in some remelting zone at the contact area, and the interface between the two droplets gradually decreases. When the second droplet comes into contact with the first droplet, the heat carried by the second droplet transfers to the first droplet, which is confirmed by the solidification of the second droplet.

To validate the numerical model, experimental observation of the end-shapes of pileups was performed to compare and validate the numerical results. Fig.5 shows

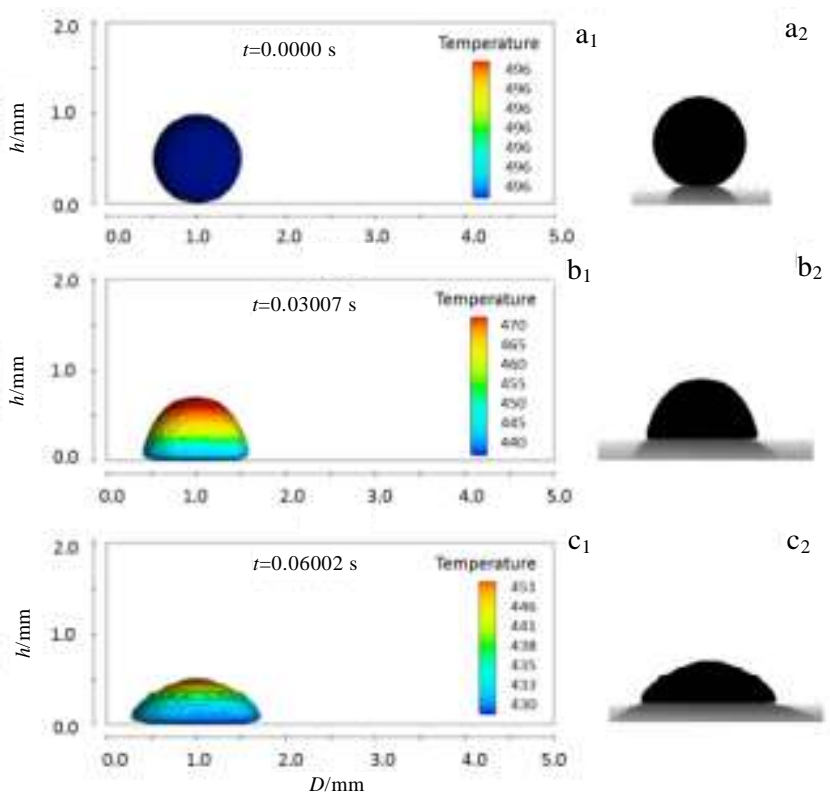

Fig.3 Simulated morphologies and temperature evolution $\left(\mathrm{a}_{1} \sim \mathrm{c}_{1}\right)$ and SEM images $\left(\mathrm{a}_{2} \sim \mathrm{c}_{2}\right)$ of an aluminum alloy droplet of 1 $\mathrm{mm}$ in diameter impacting on an aluminum substrate at different time: $\left(a_{1}, a_{2}\right) 0$ s, $\left(b_{1}, b_{2}\right) 0.03007 \mathrm{~s}$, and $\left(c_{1}, c_{2}\right) 0.06002 \mathrm{~s}$

comparison of experimental verification and numerical simulation of two aluminum droplets impacting on an aluminum substrate. The results show good qualitative agreement with experimental photographs.

At a low impact velocity $V_{0}=0.15 \mathrm{~m} / \mathrm{s}\left(\right.$ Fig. $\left.5 \mathrm{a}_{1}, 5 \mathrm{a}_{2}\right)$, the droplet reaches its maximum spread diameter at $t=0.14994 \mathrm{~s}$. The droplet finally subsides and solidifies to form a rounded pileup. When the impact velocity increases to 0.2 $\mathrm{m} / \mathrm{s}\left(\right.$ Fig. $\left.5 \mathrm{~b}_{1}, 5 \mathrm{~b}_{2}\right)$ and $0.25 \mathrm{~m} / \mathrm{s}\left(\right.$ Fig. $\left.5 \mathrm{c}_{1}, 5 \mathrm{c}_{2}\right)$, the largest circumference of the droplets increases and the solidified height decreases.

Quantitative information about the solidification can thus be extracted from the motion of the droplet by monitoring the maximum spread factor $\varepsilon_{\max }=D / D_{0}$ ( $D$ is the droplet diameter before spreading; $D_{0}$ is the droplet diameter after spreading). Fig.6 8 shows the effects of various parameters including impact velocities, substrate temperatures and droplet diameters on the maximum spread factor during impacting and spreading with solidification of a molten droplet onto an aluminum substrate surface under different parameters.

The impact velocities of the droplets have been determined to influence the maximum spreading factor $\varepsilon_{\max }$. Fig. 6 presents the evolution of $\varepsilon_{\max }$ during impacting of a molten aluminum alloy droplet on an aluminum surface at temperature of $350 \mathrm{~K}$ with velocity of $1 \sim 3 \mathrm{~m} / \mathrm{s}$. When the droplet impacts and spreads without solidification, the 


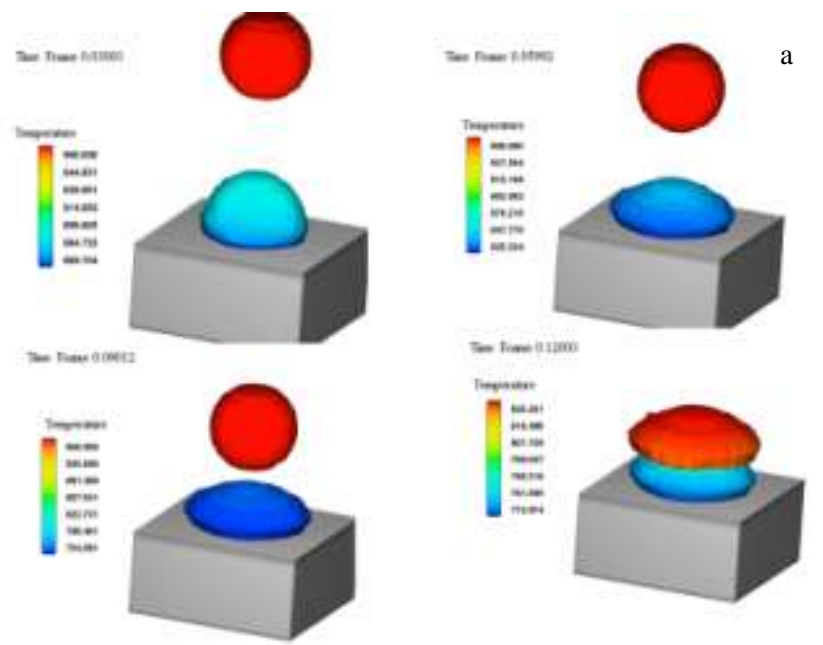

b

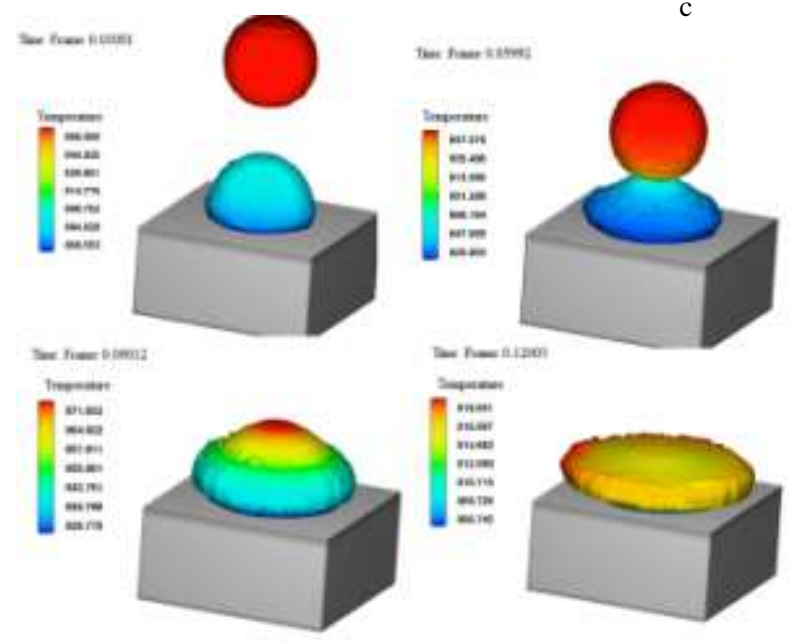

Fig.4 Simulation deformation and temperature distribution of two aluminum droplets impacting on an aluminum substrate at different velocities: (a) $V_{1}=0.15 \mathrm{~m} / \mathrm{s}$, (b) $V_{2}=0.20 \mathrm{~m} / \mathrm{s}$, and (c) $V_{3}=0.25 \mathrm{~m} / \mathrm{s}$

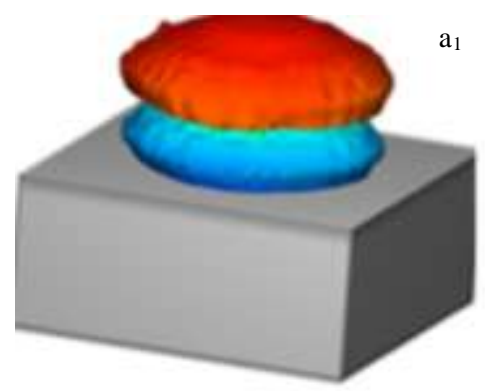

$a_{2}$

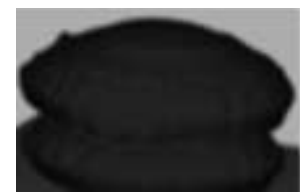

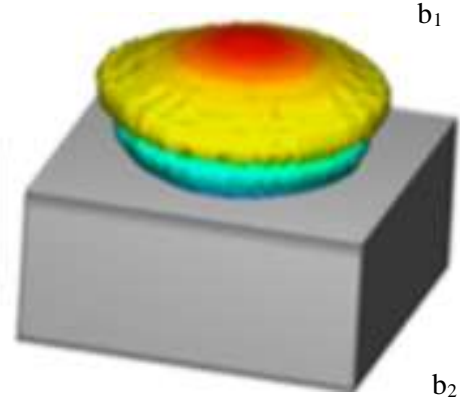

$\mathrm{b}_{2}$

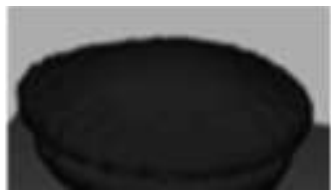

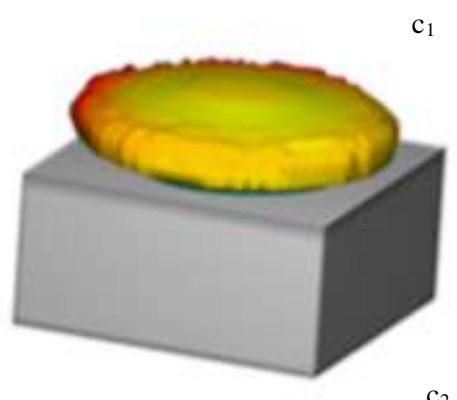

$\mathrm{c}_{2}$

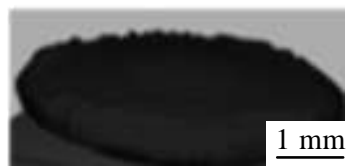

Fig.5 Simulated morphologies $\left(\mathrm{a}_{1} \sim \mathrm{c}_{1}\right)$ and SEM images $\left(\mathrm{a}_{2} \sim \mathrm{c}_{2}\right)$ of the two aluminum droplets impacting on an aluminum substrate with different velocities: $\left(\mathrm{a}_{1}, \mathrm{a}_{2}\right) V_{1}=0.15 \mathrm{~m} / \mathrm{s},\left(\mathrm{b}_{1}, \mathrm{~b}_{2}\right) V_{2}=0.20 \mathrm{~m} / \mathrm{s}$, and $\left(\mathrm{c}_{1}, \mathrm{c}_{2}\right) V_{3}=0.25 \mathrm{~m} / \mathrm{s}$ 


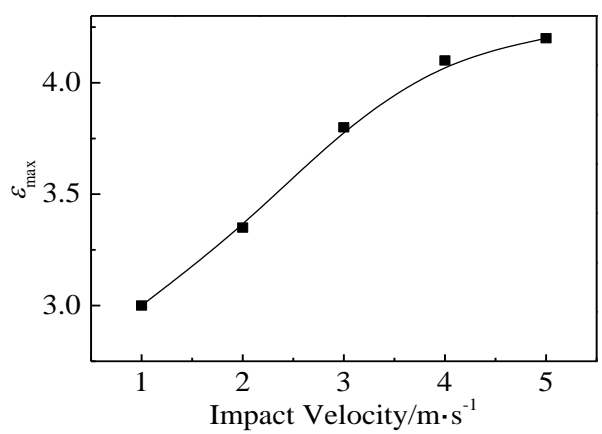

Fig.6 Results of the maximum spread factor $\varepsilon_{\max }$ vs impact velocities

faster the impact velocity, the larger the degree of the spread factor and the faster the droplet spreads. The main difference is that the maximum spread factor $\varepsilon_{\max }$ is smaller when the solidification.

As shown in Fig.7, the higher the substrate temperature $T_{\mathrm{s}}$, the larger the degree of the spread factor and the faster the droplet spreads. This is because the higher the substrate temperature, which yields a smaller temperature difference between droplet and substrate, the lower the heat transfer rate, which, in turn, allows the droplet to dissipate the energy at a slower rate.

The influence of droplet diameters on the impacting is shown in Fig.8, where maximum spread factor $\varepsilon_{\max }$ versus droplet diameters is plotted. The larger the droplet diameter, the larger the degree of the spread factor and the faster the droplet spreads.

\subsection{Experimental verification}

Fig.9 shows the surface morphology and internal microstructure of the overlap process in successive deposition. The boundary conditions were set as that: impact velocity $1.5 \mathrm{~m} / \mathrm{s}$, substrate temperature $450{ }^{\circ} \mathrm{C}$, droplet diameter $1 \mathrm{~mm}$, surrounding gas temperature $35{ }^{\circ} \mathrm{C}$.

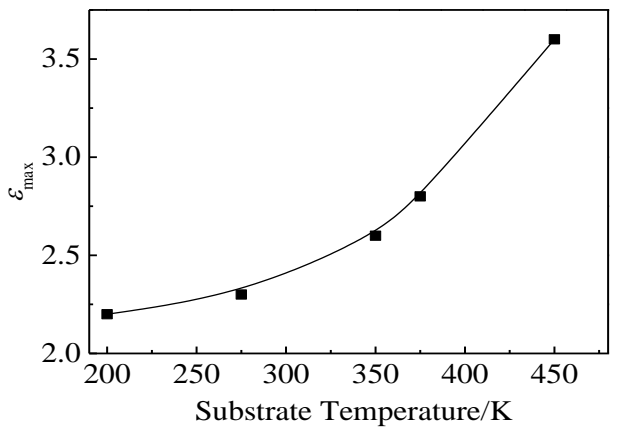

Fig.7 Results of maximum spread factor $\varepsilon_{\max }$ vs substrate temperatures

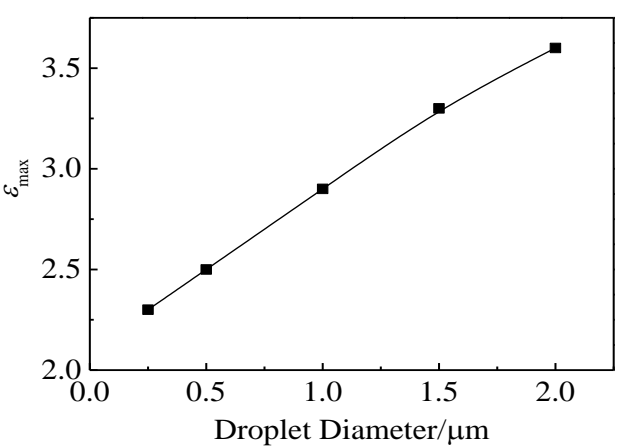

Fig.8 Results of the maximum spread factor $\varepsilon_{\max }$ vs droplet diameters

When the next droplet comes in contact with the previous one (Fig.9a), if the previous droplet is incompletely solidified at this moment, then the melt of the previous one will merge with that of the next droplet; the melt after coalescence will continually spread under the action of the initial momentum of the next one. However, the whole overlap process is retained until the droplets completely solidify (Fig.9a). These predicated droplets shapes well agree with the SEM images of uniform molten aluminum droplets onto a horizontally fixed substrate under the same conditions (Fig.9b).

Although several metal droplet-based rapid prototyping systems have been developed in recent years to fabricate functional parts, some problems still exist that need to be solved urgently, such as the poor metallurgical bonding between droplets, and cold clap (Fig.9c, Fig.9d). They show that the good metallurgical bonding between droplets is obtained under the condition of the process.

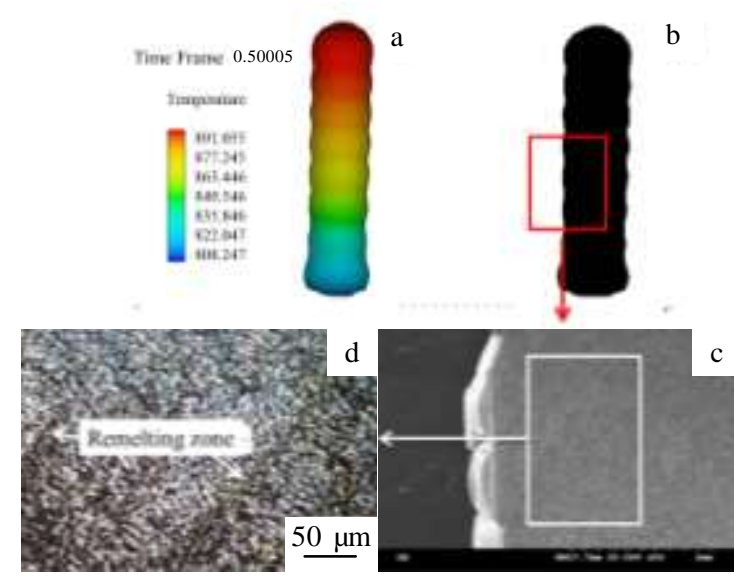

Fig.9 Numerical simulation (a) and experimental verification (b) of surface morphology and internal microstructure (c, d) of the overlap process in successive deposition 


\section{Conclusions}

1) The simulations with this model could agree well with the experimental results and provide an insight into the spreading and overlap of molten Al droplets during successively deposition, and yielded following specific results.

2) The impact velocity of the droplet has been determined to have the most important influence on the maximum spreading factor $\varepsilon_{\max }$. When the droplet impacts and spreads without solidification, the faster the impact velocity, the larger the spread factor and the faster the droplet spreads. The main difference is that the maximum spread factor $\varepsilon_{\max }$ is smaller during the solidification because when the droplet starts solidifying, the outward flow of the fluid is inhibited.

3) The higher the substrate temperature $T_{\mathrm{s}}$, the farther the droplet spreads. This is because the higher the substrate temperature (which yields a smaller temperature difference between droplet and substrate), the lower the heat transfer rate, which, in turn, allows the droplet to dissipate the energy at a slower rate. The droplet thus spreads farther before it is arrested by solidification.

4) As the droplet diameter decreases, the surface tension effect increases, exerting larger resistance against the droplet spreading. For the diameter range studied, the maximum spread factor appears to vary linearly with the droplet diameter.

\section{References}

1 Li P, Ji S Q, Zeng X Y et al. International Journal of Machine Tools and Manufacture[J], 2007, 47(6): 996

2 Chao Y P, Qi L H, Xiao Y et al. Journal of Materials Processing Technology[J], 2012, 212(2): 484

3 Cao W B, Miyamoto Y. Journal of Materials Processing Technology[J], 2006, 173(2): 209

4 Xiong X H, Zhang H O, Wang G L. Journal of Materials Processing Technology[J], 2009, 209(1): 124

5 Ando T, Chun J, Blue C. Metal Powder Report[J], 1999, 54(3): 30

6 Li S, Wu P, Zhou W et al. Materials Science and Engineering $A[\mathrm{~J}], 2008,473(1-2): 206$

7 Cheng S, Chandra S. Experiments in Fluids[J], 2003, 34(6): 755

8 Cheng $\mathrm{S} \mathrm{X}, \mathrm{Li} \mathrm{T}$ G, Chandra S. Journal of Materials Processing Technology[J], 2005, 159(3): 295

9 Fang M, Chandra S, Park C B. Journal of Manufacturing Science and Engineering [J], 2007, 129(2): 311

10 Ghafouri-Azar R, Shakeri S, Chandra S et al. International Journal of Heat and Mass Transfer[J], 2003, 46(8): 1395

11 Li S L, Wei Z Y, Du J et al. Appl Phys A[J], 2015, 120(1): 35

12 Li S L, Wei Z Y, Du J et al. Appl Phys A[J], 2016, 122(7): 677

13 Wang L Q, Yang G J, Yang H B et al. Rare Metal Materials and Engineering [J], 2009, 38(4): 579 (in Chinese)

14 Fu Q G, Li H J, Shi X H et al. Applied Surface Science[J], 2006, 252: 34750

\title{
金属熔滴连续沉积、凝固重叠工艺及实验验证
}

\author{
李素丽, 魏正英, 杜 军, 赵光喜, 王 崟鍂, 卢秉恒 \\ （西安交通大学 机械制造系统工程国家重点实验室，陕西 西安 710049）
}

\begin{abstract}
摘 要: 系统研究了铝熔滴连续沉积到基板表面的瞬态传热传质现象，采用流体体积法(VOF)对连续沉积的金属熔滴在水平固定铝基 板表面沉积进行 3D 建模。针对凝固传热过程中不同参数下熔滴在铝基板表面沉积、凝固进行了研究，通过数值计算与实验验证，各 种工艺参数的影响，如喷射速度、基板温度、熔滴直径与碰撞最大铺展因子的影响，显示了很好的一致性。基于上述研究，成形形貌 和内部微观结构之间的定量关系进一步验证了金属熔滴连续沉积、凝固重叠工艺的可行性。此工艺为金属微沉积制造实施有效的过程 控制提供指导。
\end{abstract}

关键词：金属铝液滴；连续沉积；成形形貌；内部微观结构

作者简介: 李素丽, 女, 1981 年生, 博士生, 西安交通大学机械制造系统工程国家重点实验室, 陕西 西安 710049, E-mail: 15802949318@163.com 